\title{
Quasi-16-day periodic meridional movement of the equatorial ionization anomaly
}

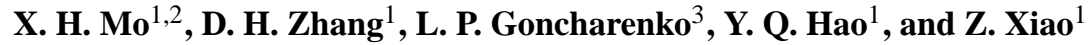 \\ ${ }^{1}$ Department of Geophysics, Peking University, Beijing, 100871, China \\ ${ }^{2}$ College of Physics and Electronic Engineering, Guangxi University for Nationalities, Nanning, China \\ ${ }^{3}$ Haystack Observatory, Massachusetts Institute of Technology, Westford, Massachusetts, USA
}

Correspondence to: D. H. Zhang (zhangdh@pku.edu.cn)

Received: 26 October 2013 - Revised: 14 January 2014 - Accepted: 15 January 2014 - Published: 18 February 2014

\begin{abstract}
Based on the daytime location of the equatorial ionization anomaly (EIA) crest derived from GPS observations at low latitude over China during the 2005-2006 stratospheric sudden warming (SSW), a quasi-16-day periodic meridional movement of EIA crest with the maximum amplitude of about 2 degrees relative to the average location of EIA crest has been revealed. In addition, periodic variations that are in phase with the meridional EIA movement are also revealed in the equatorial electrojet (EEJ) and F2 layer peak height $(h m \mathrm{~F} 2)$ over Chinese ionosonde stations Haikou and Chongqing. The quasi-16-day periodic component in Dst index is weak, and the 16-day periodic component does not exist in F10.7 index. Such large-scale periodic meridional movement of EIA crest is likely related to the globally enhanced stratospheric planetary waves coupled with anomalous stratospheric zonal wind connected with SSW. In addition, such large-scale periodic movement of EIA should be global, and can affect the ionospheric morphology around the low-latitude belt near the EIA region. Further case analysis, simulation and theoretical studies must proceed in order to understand the periodic movements of EIA connected with the different periodic atmospheric variations.
\end{abstract}

Keywords. Ionosphere (equatorial ionosphere)

\section{Introduction}

The equatorial ionization anomaly (EIA), formed by the equatorial fountain effect via the upward $\boldsymbol{E} \times \boldsymbol{B}$ drift driven by large-scale eastward electric field at the dip equator, is a common feature of the low-latitude ionosphere. Since the first report of EIA by Appleton (1946), the EIA has been extensively studied based on the ionospheric electron density data from ground-based ionosondes, topside ionospheric sounders, satellite beacon and in situ satellite measurements (e.g., Yeh et al., 2001; Lin et al., 2007; Wan et al., 2008). It is generally accepted that the EIA morphology is partly controlled by the dynamics of the mesosphere and lower thermosphere (MLT), which is affected on both temporal and spatial scales by different atmospheric motions, such as global-scale atmospheric flows and various atmospheric waves including gravity waves, tides, and planetary waves (Fejer, 1991; Forbes, 1996). Due to the modulation of the ionosphere by different atmospheric waves through electro-dynamic processes, many parameters are related to the ionosphere incorporate atmospheric wave signatures (Fejer, 1991; Forbes, 1996). Using the global-scale observations for the oxygen nightglow emission at $135.6 \mathrm{~nm}$ and the ionospheric electron density parameters, a remarkable longitudinal wavenumber 4 (WN4) structure was found in the low-latitude ionosphere and attributed to the influences of the global-scale atmospheric non-migrating DE3 tides through vertical coupling processes (e.g., Hagan and Forbes, 2002; Immel et al., 2006; Sagawa et al., 2005; Wan et al., 2008). In addition, the evidence of periodic planetary waves was also demonstrated in many ionospheric parameters, including the equatorial electrojet (EEJ) index, vertical plasma drift velocities, electron density, and F layer peak height (Abdu et al., 2006; Parish et al., 1994; Vineeth et al., 2007; Fagundes et al., 2005; Pedatella and Forbes, 2009; Liu et al., 2011). For example, Abdu et al. (2006) provided evidence of planetary waves with 4-day and 7-day periods in the vertical drift plasma velocity based on meteor radar and digisonde data over low-latitude sites in Brazil. Fagundes et al. (2005) investigated how the 
F layer virtual height was modulated by planetary waves with period of 9-17 days.

A series of recent reports concerning ionospheric perturbations associated with lower atmospheric forcing have focused on sudden stratospheric warming (SSW). These reports mainly discussed the features of the ionospheric variation in low-latitude region, the possible connections between the state of the atmosphere at low latitude and high latitude, and the possible connections between the ionosphere and MLT region related to SSW (Chau et al., 2009, 2010; Goncharenko et al., 2010a, b; Mukhtarov et al., 2010; Pedatella and Forbes, 2009; Vineeth et al., 2007, 2010). Using the global reanalysis data of atmospheric temperature and wind provided by the National Centers for Environmental Prediction (NCEP) and National Center for Atmospheric Research (NCAR), Vineeth et al. (2010) found an enhanced planetary wave (PW) activity of quasi-16-day periodicity in the stratosphere propagating from the Equator to the North Pole during several SSW years. Vineeth et al. (2010) suggested that these poleward propagating planetary waves are related to the rapid increase of the polar stratospheric temperature. The large persistent variations in the low-latitude ionosphere that occurred several days after the peak of SSW in 2008 and 2009 were interpreted in terms of large changes in atmospheric tides resulting from their nonlinear interaction with planetary waves that were strengthened during sudden warmings (Goncharenko et al., 2010a, b). Based on equatorial magnetometer data from December 2005 to March 2006 when a SSW event occurred, Vineeth et al. (2007) identified a quasi-16-day periodic oscillation in the EEJ. Using the ionospheric electron densities from the CHAllenging Minisatellite Payload (CHAMP) satellite and ionospheric total electron content (TEC) data from GPS during the same period, Pedatella and Forbes (2009) found the quasi-16-day oscillation in these density parameters at low latitude and suggested that vertically propagating planetary waves induce significant variability in the low-latitude F region ionosphere. More recently, using ionospheric TEC from GPS observations in the Indian sector, Sripathi and Bhattacharyya (2012) also studied the ionospheric periodic variability during 2005-2006 SSW event and suggested that this kind of periodic variability in TEC is caused by the nonlinear interaction of upward propagating planetary waves with atmospheric tides. In their study, the quasi-periodic oscillation of the latitude of the EIA crest was revealed qualitatively. These reports reveal different aspects of ionospheric variation at low latitudes and are useful for grasping the connection between the ionospheric variations and atmospheric condition globally during SSW periods.

The motion of the EIA crest has been shown to be an excellent proxy for the strength of the dynamo electric field (Yeh et al., 2001). Due to the close relationship between the tidal wind in the lower thermosphere, the zonal electric fields, and the EIA behavior, it is undoubtedly an interesting problem to find the signatures of the variation in MLT region from the latitudinal location of the EIA crest. In this paper, we use dual-frequency GPS data collected in the China low-latitude region to study the movement of the EIA crest location during the 2005-2006 SSW event. The key questions to be answered in this paper are the following: (1) whether the effect of this SSW event on EIA crest exists and can be detected in the location parameter of EIA crest from GPS observations, and (2) if detectable, does the periodic oscillation in low-latitude ionospheric TEC found in some studies exist in EIA crest and what is the oscillation range of EIA crest?

\section{Data and methods}

The GPS data with 30 s sample rate observed at three GPS stations located at China low latitudes during the period from 1 December 2005 to 31 March 2006 are used to derive the location of the daytime EIA crest. The GPS stations ID and their geographic and geomagnetic location are listed in Table 1 . The spatial coverage in the zonal direction for these stations is about $1000 \mathrm{~km}$, and their geomagnetic latitudes are between $12^{\circ} \mathrm{N}$ to $14^{\circ} \mathrm{N}$ (e.g., near the EIA crest region in China longitudinal sector). The temporal ionospheric vertical TEC at each ionospheric pierce point (IPP) (i.e., the intersection between the line of sight from satellite to receiver and the ionospheric thin shell) can be derived from every continuous GPS satellite-receiver observation arc (Mannucci et al., 1998; Zhang and Xiao, 2005). If the IPP trajectory of the satellite-receiver observation arc passes through the EIA crest region in the daytime, the ionospheric TEC will reach the maximum at the cross-point between the EIA peak and the IPP trajectory, and then the location of the EIA crest at certain time can be accurately captured. For the convenience of determining the local time and the latitude of the captured EIA peak point, the IPP trajectory of the satellitereceiver observation arc is converted into the latitude and the local time coordinate. The IPP's local time is calculated based on the IPP's universal time and IPP's longitude $(\mathrm{LT}=\mathrm{UT}+\mathrm{Long} / 15)$. Figure 1 shows the variation of IPP latitude of all GPS satellites with corresponding IPP local time on 12 March 2006 observed at GUAN station, and the vertical TEC values on the trajectory are given in color scale. From this figure, the latitude of several EIA crest points and their corresponding local times (shown in black dots) can be obtained from every continuous GPS tracking arc. It should be mentioned that because the sample rate of GPS data is $30 \mathrm{~s}$, the spatial resolution of the obtained crest location in our method is about $20-25 \mathrm{~km}$.

In this study, the locations of the daytime EIA crest over these GPS station regions are derived for the period 1 December 2005-31 March 2006 from the temporal TEC curves using the above-mentioned processing. Yeh et al. (2001) showed that the EIA peak usually reaches most northern latitude at about 12:00-14:00 LT. In order to determine the EIA peak from each TEC curve, only EIA peak points between 
Table 1. The GPS station IDs and their geographic and geomagnetic location.

\begin{tabular}{lrrrr}
\hline GPS station ID & $\begin{array}{r}\text { Geographic } \\
\text { latitude (degree) }\end{array}$ & $\begin{array}{r}\text { Geographic } \\
\text { longitude (degree) }\end{array}$ & $\begin{array}{r}\text { Geomagnetic } \\
\text { latitude (degree) }\end{array}$ & $\begin{array}{r}\text { Geomagnetic } \\
\text { longitude (degree) }\end{array}$ \\
\hline GXUN & 22.84 & 108.33 & 12.14 & 179.75 \\
GUAN & 23.19 & 113.34 & 12.52 & -175.53 \\
XIAM & 24.45 & 118.08 & 13.89 & -170.11 \\
\hline
\end{tabular}

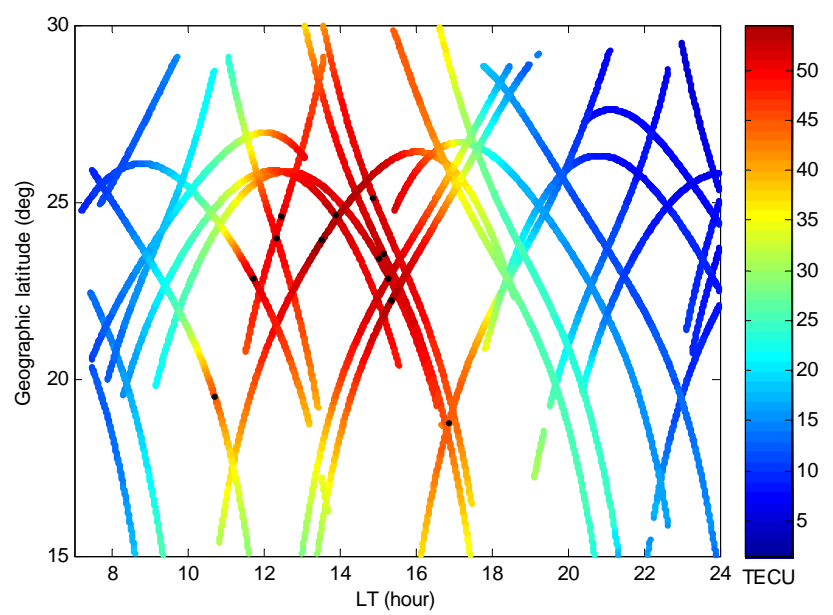

Fig. 1. The relationship of the IPP's geographic latitude with corresponding local time for all satellite-receiver tracking arcs in 12 March 2006 over GUAN GPS station. The ionospheric TEC values are given in color scale, and the location of EIA crest is marked in black dot.

10:00 and 16:00 LT are used. In addition, considering the larger error of the calculated TEC from lower elevation observations, the EIA peak points with elevation less than 30 degrees are further removed. Because the selected GPS stations are near the northern EIA crest region, this limitation is met easily for the great majority of the collected EIA peak points. Figure $2 \mathrm{a}-\mathrm{c}$ give the latitudinal variation of the collected EIA peak points from GPS observations observed at three GPS stations during 1 December 2005 to 31 March 2006 (a: GUXN; b: GUAN; c: XIAM), the red line represents the daily latitude of EIA peak by averaging the latitudes of every day's EIA peak points, and the blue dashed line represents the latitude of EIA peak by averaging all days' EIA peak latitude during this period. To present the variation of the EIA crest in geomagnetic coordinate system, all of the derived geographic locations of the EIA crest are converted into their corresponding geomagnetic locations using the International Geomagnetic Reference Field model. It can be seen that the average geomagnetic latitude of EIA crest in China longitudinal sector during this period is about $10^{\circ} \mathrm{N}$.

Besides the latitudinal location of EIA crest derived from GPS data, some other data in the same period are also used, including EEJ, $h m \mathrm{~F} 2$, foF2, Dst and F10.7 indices. Rastogi and Klobuchar (1990) estimated the EEJ from the difference of the horizontal component of the geomagnetic field observed by two ground-based magnetometers located at the magnetic equatorial and the tropical latitude respectively, and they found the extent of the latitudinal anomaly was directly related to the strength of the equatorial electrojet represented by the daily average EEJ estimated from the geomagnetic field data during the period from 07:00 to 14:00 LT. Through the correlative study of the vertical drift velocity observed by Jicamara incoherent scatter radar (ISR) and the EEJ index in the Peruvian sector, Anderson et al. (2002) verified the linear and positive relationship between the vertical drift velocity in ionospheric $F$ region and the daytime strength of EEJ. In our study, the EEJ index is used as a proxy to present the strength of zonal electric field and the vertical drift velocity. The selected two geomagnetic stations are BCL at Bac Lieu in Vietnam and YON at Yongning in China. Their geographic and geomagnetic positions are given in Table 2. In addition, the $h m \mathrm{~F} 2$ and $f_{o} \mathrm{~F} 2$ data observed at Chinese ionosonde station Haikou (geographic location: $20.02^{\circ} \mathrm{N}, 110.20^{\circ} \mathrm{E}$; geomagnetic location: $9.32^{\circ} \mathrm{N}$, $-178.46^{\circ} \mathrm{E}$ ) and Chinese ionosonde station Chongqing (geographic location: $29.59^{\circ} \mathrm{N}, 106.54^{\circ} \mathrm{E}$; geomagnetic location: $18.89^{\circ} \mathrm{N}, 178.11^{\circ} \mathrm{E}$ ) are also used for comparative studies. Figure $2 \mathrm{~d}-\mathrm{f}$ give the day-to-day variation of daily average EEJ in the China sector, foF2 and $h m \mathrm{~F} 2$ at 12:00 LT at Haikou and Chongqing stations. The $h m \mathrm{~F} 2$ is derived based on the empirical relation that includes the parameters of $\mathrm{M}(3000) \mathrm{F} 2$, foF2 and foE (Bradley and Dudeney, 1973). It should be noted that geomagnetic latitude of Haikou station is $9.32^{\circ} \mathrm{N}$, which is located near the average latitude of the northern EIA crest, and the geomagnetic latitude of Chongqing station is $18.89^{\circ} \mathrm{N}$, which is always located in the north side of the northern EIA crest.

\section{Results}

Figure 2 demonstrates that the location of EIA crest determined from three independent stations positioned up to $1000 \mathrm{~km}$ apart (GXUN, GUAN and XIAM) undergoes similar variations during the winter 2005/2006. These variations are seen as a series of simultaneous increases (days $\sim 48-52$ ) and decreases (days 42-44, 57, 68-72) in EIA crest magnetic latitude. These increases and decreases coincide with 
Table 2. The location information of the geomagnetic station used in this study.

\begin{tabular}{lrrrr}
\hline Station ID & $\begin{array}{r}\text { Geographic } \\
\text { latitude (degree) }\end{array}$ & $\begin{array}{r}\text { Geographic } \\
\text { longitude (degree) }\end{array}$ & $\begin{array}{r}\text { Geomagnetic } \\
\text { latitude (degree) }\end{array}$ & $\begin{array}{r}\text { Geomagnetic } \\
\text { longitude (degree) }\end{array}$ \\
\hline BCL & 9.3 & 105.7 & -1.398 & 177.14 \\
YON & 22.74 & 108.49 & 12.04 & 179.91 \\
\hline
\end{tabular}
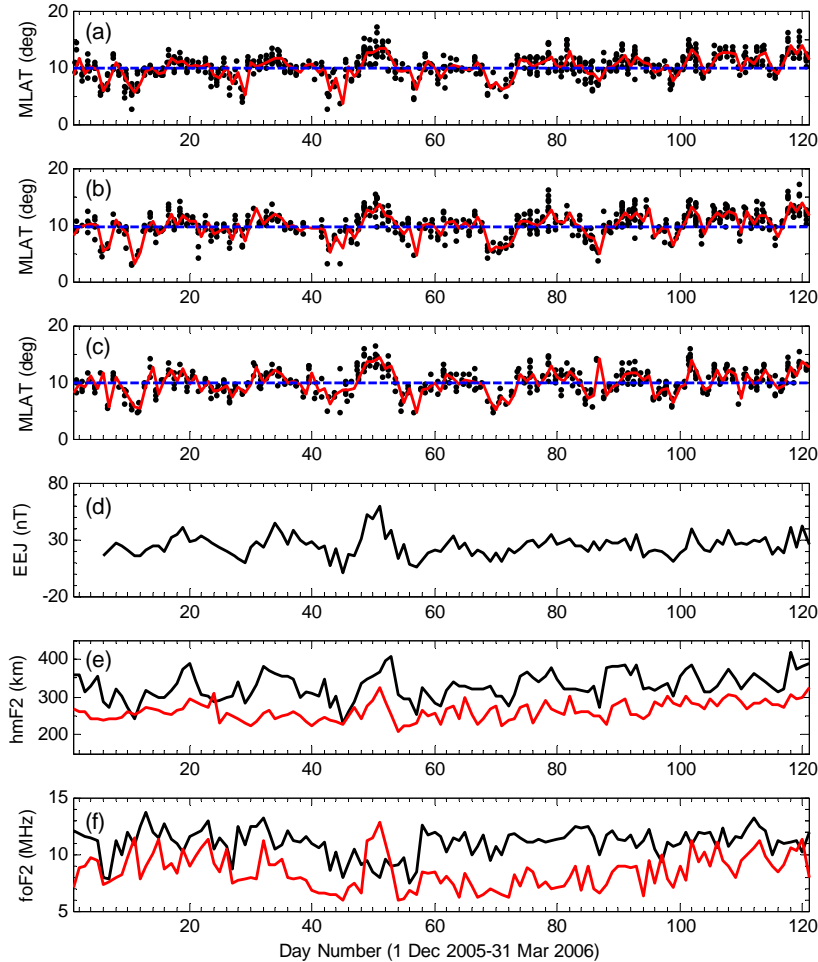

Fig. 2. The MLAT location of EIA crest derived from GXUN, GUAN and XIAM GPS measurements during the period from 1 December 2005 to 31 March 2006 ((a) GUXN; (b) GUAN; (c) XIAM), the blue dashed line represents the average latitude of EIA peak during this period, and the red line represents the daily average of latitude of these EIA peak points; (d) EEJ data derived from geomagnetic data from BCL and $\mathrm{YON}$; (e) $h m \mathrm{~F} 2$ and (f) $f o \mathrm{~F} 2$ data observed at Chongqing (red line) and Hainan (black line) ionosonde stations.

similar variations in the strength of EEJ, indicating that location of the crest is controlled by the variation in the vertical drift. Ionosonde data are consistent with this interpretation, demonstrating increase in $h m \mathrm{~F} 2$ in both ionosonde stations during stronger EEJ and northward movement of EIA (days 48-52). In addition, peak electron density $N m \mathrm{~F} 2$ is strongly increased at Chongqing (north side of EIA crest) during this time, while $N m \mathrm{~F} 2$ at Haikou (average crest latitude) shows complex variations.

Lomb-Scargle (L-S) periodogram (Lomb, 1976; Scargle, 1982 ) is an effective method to reveal the periodic information from time-series data (Lei et al., 2008). Figure 3 gives the $\mathrm{L}-\mathrm{S}$ periodogram results of the magnetic latitude
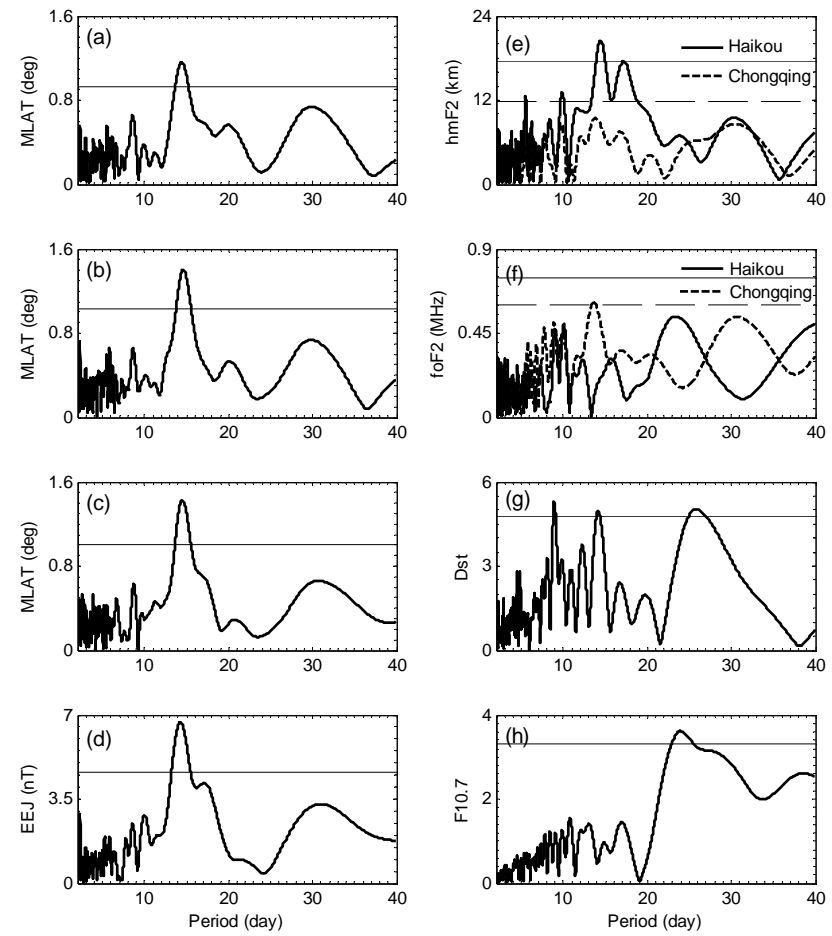

Fig. 3. Lomb-Scargle periodograms of MLAT location of EIA crest above GXUN, GUAN and XIAM GPS stations (a-c); (d) EEJ; (e) $h m \mathrm{~F} 2$ with dashed line for Chongqing and solid line for Haikou; (f) $f o \mathrm{~F} 2$ with dashed line for Chongqing and solid line for Haikou; (g) Dst index; and (h) F10.7 index during the same period as in Fig. 2.

(MLAT) of the EIA crest derived from GPS data observed at station GXUN, GUAN and XIAM, EEJ derived from horizontal components of geomagnetic fields observed in China sector, $h m \mathrm{~F} 2$ and $f o \mathrm{~F} 2$ at Chinese stations Haikou and Chongqing, Dst index and daily F10.7 index during the period from 1 December 2005 to 31 March 2006. The horizontal dashed line in each sub-panel represents the $95 \%$ confidence level for the corresponding parameters. It can be seen in Fig. 3 that the EIA crest derived from three GPS stations exhibits a significant 14-day periodic component that was usually termed the quasi-16-day periodic variation. This indicates that the EIA crest moves in meridional direction back and forth with an obvious 14-day period during this time period that has not been found before. Vineeth et al. (2007) and Pancheva et al. (2002) found that the variations of EEJ 
and $h m \mathrm{~F} 2$ coincided with the equatorial zonal electric field. For comparison, in Fig. 3 our results show that the EEJ and $h m \mathrm{~F} 2$ parameters exhibit obvious quasi-16-day periodic component, but the behavior of $f o \mathrm{~F} 2$ at two ionosonde stations is a little different. The $f_{o} \mathrm{~F} 2$ at Chongqing station exhibits notable quasi-16-day component, whereas the $f o \mathrm{~F} 2$ at Haikou station exhibits no similar component. In addition, although above $95 \%$ confidence level, this kind of quasi-16day periodic component is a little weaker than 9-day and 27day periodic components in Dst index. And the F10.7 index does not exhibit this component at all. This agrees with the study by Pedatella and Forbes (2009) on Kp and SOHO-SEM 0.1-50 nm extreme-ultraviolet (EUV) flux during almost the same time period. Therefore, our results indicate that this 14day periodic meridional movement of EIA crest is not directly related to solar EUV irradiance and is weakly related to geomagnetic activity. As for the different behavior of $f o \mathrm{~F} 2$ at Chongqing and Haikou station, we will discuss this in the remaining part of this paper.

Besides the 14-day periodic component in the latitudinal location of EIA crest, EEJ and $h m \mathrm{~F} 2$, some other periodic components in different parameters are shown in Fig. 3, such as the quasi-27-day periodic component in all parameters and the 9-day periodic component in Dst, $h m \mathrm{~F} 2$ and foF2. The 27-day periodic component in these parameters was usually attributed to the solar rotation effect (Oinats et al., 2008). The 9-day period presented in Dst and Kp was attributed to periodic high-speed streams in solar wind (Lei et al., 2008). Mukhtarov et al. (2010) gave more detailed analysis on these planetary wave type responses in the thermosphere/ionosphere system to forcing from above and below during the same period. They concluded that the observed global ionospheric zonally symmetric oscillations with periods of 9, 14 and 24-27 days were of solar origin. The 18day westward propagating wave with zonal wavenumber 1 , observed in the ionospheric currents, and in $f o \mathrm{~F} 2$ and TEC could be associated with a simultaneous 18-day westward propagating planetary wave observed in the stratosphere and MLT region.

In addition, Fig. 3 demonstrates other periodic components in MLAT location of EIA crest; for example, a weaker but distinguishable quasi-27-day periodic component exists in MLAT location of EIA. It will be discussed in detail in our future studies.

To examine the time evolution of the 16-day periodic variation, the results of Morlet wavelet spectral analysis on MLAT location of EIA crest, EEJ, $h m$ F2, Dst and F10.7 index are given in Fig. 4, with black contour lines in each panel representing the $95 \%$ confidence level. The white line in each panel represents the cone of influence of the wavelet analysis. In addition, Fig. 4 shows the polar stratospheric temperature $\left(90^{\circ} \mathrm{N}, 10 \mathrm{hPa}\right)$ from NCEP (dashed line). It can be seen that the polar stratosphere exhibited three intermittent warmings that occurred during day number 3580. The dominant periodic component in MLAT location of
EIA crest, EEJ, and $h m \mathrm{~F} 2$ over Haikou and Chongqing is the quasi-16-day periodicity. However, the time evolution of this periodic component in these parameters is a little different. For the MLAT location of EIA crest, the 16-day periodic variation lasts about 60-70 days (day number 20-90). For EEJ index, this component lasts about 50 days (day number 20-70). For $h m \mathrm{~F} 2$ parameter, this component at Haikou station lasts longer (day number 20-70) than that at Chongqing station (day number 40-60). Although there are some differences in time evolution for the variation of these parameters, from the similar time evolution of the variation of MLAT location of EIA crest over GPS stations that are $1000 \mathrm{~km}$ apart in zonal direction, it can be concluded that the EIA crest over China longitudinal sector exhibited quasi-16-day periodic movement in meridional direction during this time period.

In order to show the phase relationship of the periodic variations in these parameters, the band-pass filter results for the percent residuals of location of EIA crest, EEJ and $h m \mathrm{~F} 2$ to 16 -day running mean are obtained, with the window of the 16-day mean centered on the day when the parameters are observed. The band-bass filter is centered at the period of 16 days, with half-power points at 12 days and 20 days. As shown in Fig. 5, the meridional movement of EIA crest above GXUN, GUAN and XIAM are well correlated and in phase with the variations of EEJ and $h m \mathrm{~F} 2$. All parameters reach the maximum amplitudes around day number 50 , which is about several days ahead of the peak temperature during the stratospheric warming. The linear correlation coefficient between the MLAT of EIA obtained in GXUN and GUAN is 0.97, and it is 0.94 between the MLAT of EIA in GUXN and EEJ. The latitudinal range due to the 16-day periodic movement of EIA crest in meridional direction is about $20 \%$ relative to the average location of EIA crest in this longitudinal sector. Considering the average latitude of EIA crest shown in Fig. 2, this range is equivalent to 2 degrees or about $200 \mathrm{~km}$ in meridional direction. The height range corresponding to the 16-day periodic movement of the ionospheric F2 peak height in vertical direction is about $10 \%$ at Haikou station and $8 \%$ at Chongqing station relative to their average $h m \mathrm{~F} 2$ heights. For example, the height range is about $35 \mathrm{~km}$ at Haikou station and about $20 \mathrm{~km}$ at Chongqing station.

\section{Discussions}

Both the winds and the electric fields produce plasma drifts that alter the ionospheric electron density distribution. Over the low latitudes, the earth's magnetic field lines are almost horizontally oriented, and this leads to a condition in which the dynamo electric fields generated by the globalscale waves play a leading role in the associated response of the ionospheric $\mathrm{F}$ region. 

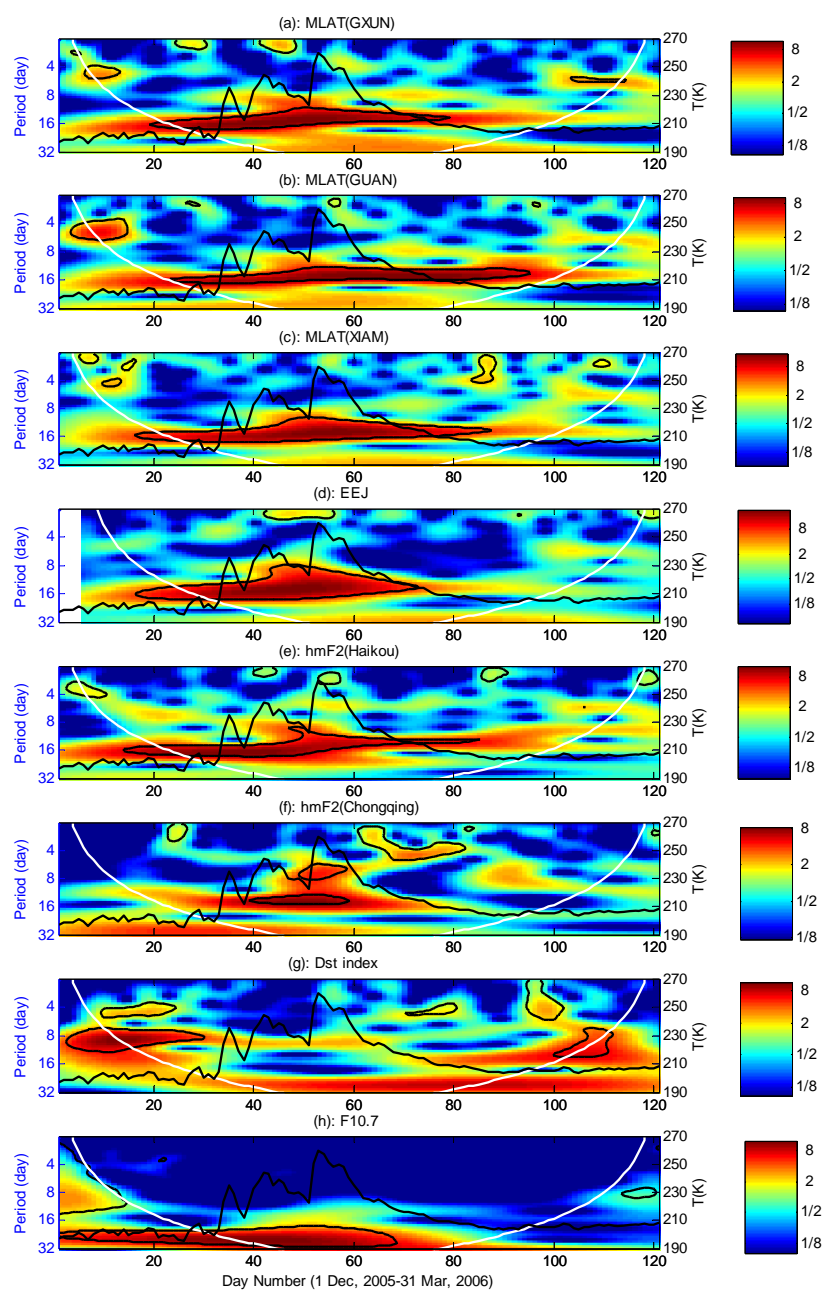

Fig. 4. The wavelet power spectra of MLAT location of EIA crest peaks above GXUN, GUAN and XIAM GPS stations (a-c), EEJ (d), $h m \mathrm{~F} 2$ at Haikou (e) and $h m \mathrm{~F} 2$ at Chongqing (f), Dst (g) and F10.7 (h) during the same period as in Fig. 2. The dashed line in each panel represents the polar stratospheric temperature from NCEP during the same period, and the white line in each panel represents the cone of influence of the wavelet analysis.

According to the equatorial plasma drift theory, it is reasonable to deduce that the MLAT location of the EIA crest is connected with the maximum height of plasma transport in the equatorial region, which is controlled by the strength of the "pumping force" or the vertical $\boldsymbol{E} \times \boldsymbol{B}$ drift velocity in the height of ionospheric $\mathrm{F}$ region. And the features of the periodic variation of zonal electric field should be revealed in the ionospheric F2 peak height, even in the MLAT location of EIA crest formed. According to meteor radar measurements in high latitude, Pancheva and Mitchell (2004) found the strong planetary-wave-scale disturbances in the mesosphere and low thermosphere that were caused by the nonlinear coupling of planetary waves and semidiurnal tide, though it is not clear if these periodicities are still present at lower
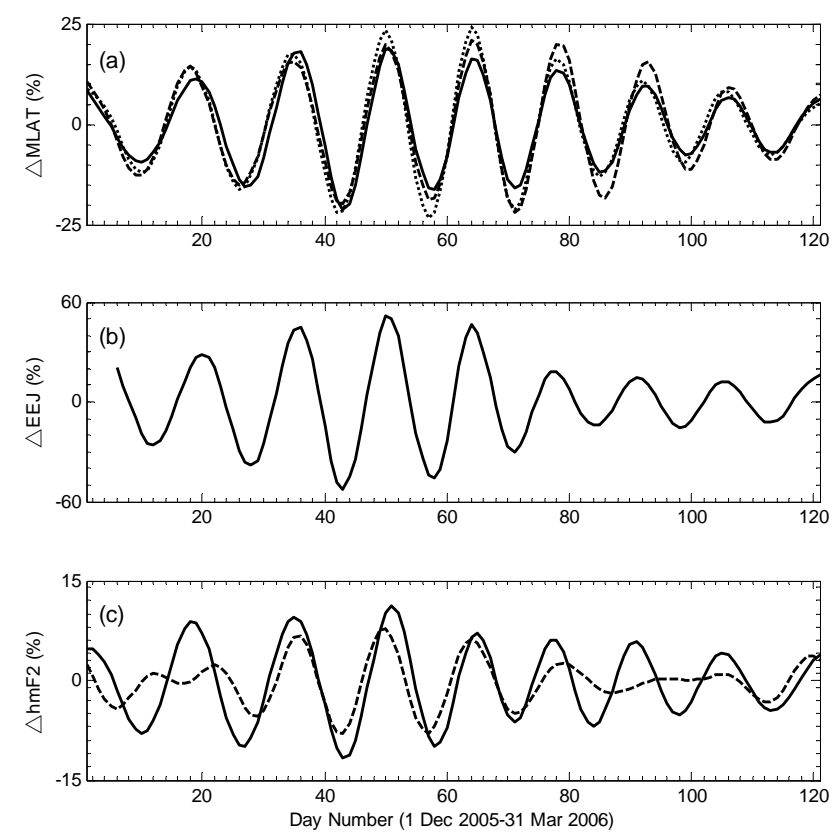

Fig. 5. The band-pass filter results of the percent residuals of MLAT location of EIA crest, EEJ and $h m \mathrm{~F} 2$ to 16-day running mean of GXUN (solid line), GUAN (dashed line) and XIAM (dot line) GPS stations (a), EEJ (b), and hmF2 (c) (dashed line: Chongqing, solid line: Haikou) during the same period as in Fig. 2.

latitudes. Nonlinear interaction of planetary waves and tides can generate secondary waves with periods close to $12 \mathrm{~h}$ that might attain high amplitudes in the MLT region. Pancheva et al. (2002) reported 16-day oscillation in $h m \mathrm{~F} 2$ at mid-latitude and attributed it to the modulation of semidiurnal tide and 16day planetary wave observed in the MLT. Abdu (2006) found that the planetary wave modulating the E region tidal winds leads to planetary-wave-scale oscillations in the plasma vertical drift velocity in the equatorial ionosphere. Recent studies revealed that quasi-16-day periodicity was observed in the equatorial mesopause and lower thermosphere temperature, electron density and TEC in EIA region, and EEJ during the same time period due to the quasi-16-day planetary wave modulating the tidal amplitudes in the ionospheric dynamo region (Vineeth et al., 2007; Pedatella and Forbes, 2009; Sripathi and Bhattacharyya, 2012). Besides the mechanism of the nonlinear interaction of upward propagating 16-day periodic planetary wave with atmospheric tides, the strongly enhanced semidiurnal lunar tide has also been noted and has been considered to explain the quasi-16-day periodic variation observed in EEJ and ionosphere in some SSW case studies (Fejer et al., 2010; Eccles et al., 2011). Although the exact mechanism remains to be understood, it is generally accepted that the changing zonal winds during SSWs play an important role in the coupling between ionospheric variability and the forcing from planetary waves of lower atmospheric origin during SSWs (Vineeth et al., 2007; Pedatella and 
(a): Temperature, $\mathrm{K}$

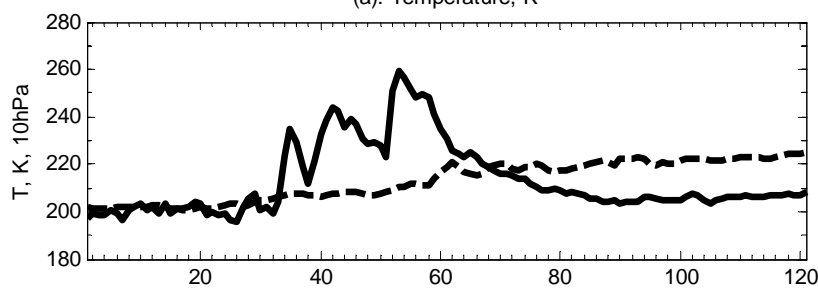

(b): Zonal mean zonal wind, $60^{\circ} \mathrm{N}$

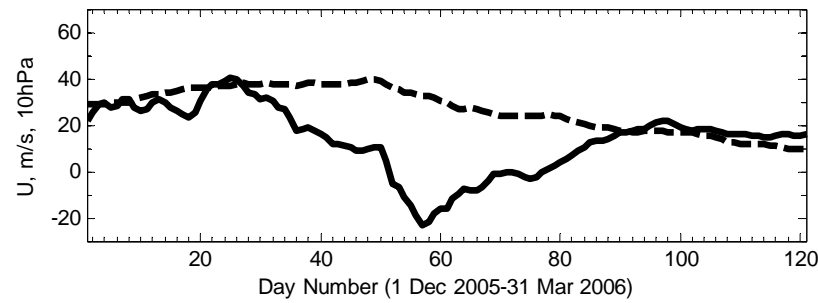

Fig. 6. Summary of stratospheric conditions for the winter of 2005 2006. (a) Stratospheric temperature at $90^{\circ} \mathrm{N}$ and $10 \mathrm{hPa}(\sim 32 \mathrm{~km})$ (solid line), (b) zonal mean zonal wind at $60^{\circ} \mathrm{N}$ and $10 \mathrm{hPa}$ (solid line). The dashed lines are the multiyear means of the corresponding parameters.

Forbes, 2009; Goncharenko et al., 2010b). Figure 6 presents the stratospheric temperature at $90^{\circ} \mathrm{N}$ and $10 \mathrm{hPa}(\sim 32 \mathrm{~km})$ and zonal mean zonal wind at $60^{\circ} \mathrm{N}$ from NCEP. The black lines represent the data during the 2005-2006 SSW, and the dashed lines are multiyear means (averaged from 1978 to 2008). It can be seen that, before the polar temperature increases, the zonal-mean stratospheric wind at $60^{\circ} \mathrm{N}$ decreases gradually relative to its multiyear means and even changed its direction from eastward to westward during day number 5070. The largest absolute change of zonal mean zonal wind was as high as $30 \mathrm{~m} \mathrm{~s}^{-1}$ relative to the multiyear averaged one, and the largest westward velocity occurred at about day number 57 . The temporal extent of the zonal wind anomaly (day number $\sim 30-85$ ) is significantly larger than the temporal extent of the stratospheric temperature anomaly (day numbers $\sim 35-65$ ). The stratospheric zonal wind anomaly coincides with the increased amplitude of quasi-16-day oscillations in ionospheric parameters presented in Fig. 4. This further indicates that variation in the zonal mean wind (and not variation in the stratospheric temperature) is the important parameter controlling the efficiency of connections between the stratosphere and the ionosphere.

Vineeth et al. (2010) revealed the connection of the enhanced PW activity in the stratosphere between the Equator and the North Pole during several SSW years. To examine the connection between the SSW and quasi-16-day variation in EIA location further, the amplitudes of planetary wave 1 and 2 calculated from NCEP geopotential height data at $60^{\circ} \mathrm{N}$ and $10 \mathrm{hPa}$ are presented in Fig. $7 \mathrm{a}$ and b. As shown in this figure, the activity of planetary wave 1 was very high during the first part of the winter, up to the day
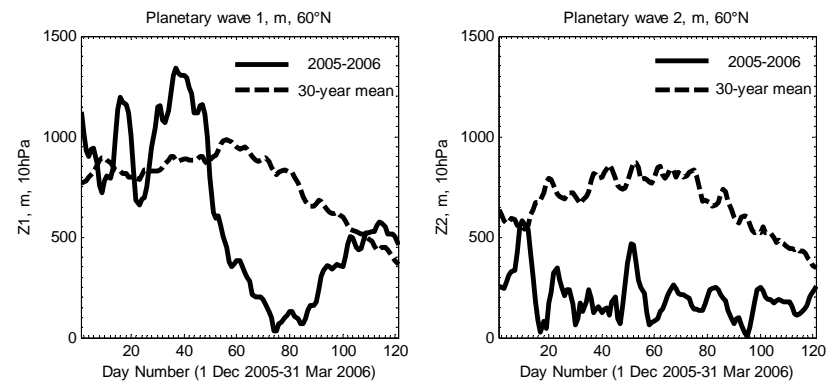

Fig. 7. The amplitude of planetary wave 1 (left) and 2 (right) in geopotential height at $60^{\circ} \mathrm{N}$ and $10 \mathrm{hPa}$ during the SSW period.

$\sim 50$. This amplification in planetary wave activity also has a period close to $\sim 16$ days, and can contribute to the quasi16-day oscillations reported in this study. However, planetary wave 1 activity sharply decreases after the development of SSW (after day $\sim 50$ ). This is a typical feature of SSW development, as tropospherically generated planetary waves do not propagate to the stratosphere during the mature stage of SSW because of the changed zonal flow (Limpasivan et al., 2004). In addition, activity of planetary wave 2 is low all winter (Fig. 7b), and is not expected to produce strong periodic oscillations in ionospheric parameters. We thus suggest that the globally changed stratospheric zonal wind system shown in Fig. 6 seems propitious to the existence of quasi-periodic variations in the MLT region and ionosphere.

Recent numerical simulations further confirmed significance of the stratospheric zonal wind changes that occur during SSW events for the modification of the MLT region and ionosphere. Jin et al. (2012) used simulations by Ground-totopside model of Atmosphere and Ionosphere for Aeronomy (GAIA) model to demonstrate that SSW-related anomalies in the zonal mean wind lead to the global amplifications of the solar semidiurnal tide. Forbes and Zhang (2012) concluded that changes in the zonal wind in connection with SSW are responsible for the amplification of lunar tide. Pedatella and Liu (2013) investigated importance of planetary wave amplitude and zonal wind for the modification of tides in the MLT region using Whole Atmosphere Community Climate Model (WACCM) simulations, and concluded that changes in the zonal mean atmosphere are the dominant reason for the amplification of the solar and lunar semidiurnal tides. Since the cycle of the lunar age is 29.53 days, the semidiurnal lunar tide has a periodicity of 14.76 days, which is consistent with periodicity observed in our ionospheric data (Figs. 3 and 5). Figure 5 also indicates that quasi-16-day variations were observed throughout all winter, but were strongly amplified between days 30 and 80 (e.g., when the stratospheric wind was strongly disturbed; Fig. 6). This further supports our suggestion that periodic variations reported in this study at least partially can be related to lunar tides that are consistently present in the atmosphere and become strongly enhanced 
during SSW events (Pedatella and Forbes, 2010; Fejer et al., 2010; Fejer, 2011; Yamazaki, 2013).

Mukhtarov et al. (2010) used SABER/TIMED temperature and solar wind velocity data to identify a zonally symmetric oscillation with 14-day period in ionosphere that was considered to be of solar origin and a 18-day westwards propagating planetary wave with zonal wavenumber 1 in stratosphere and MLT region at $50^{\circ} \mathrm{N}$. Vineeth et al. (2007) showed the obvious quasi-16-day periodic variation in equatorial mesopause temperature observed in the Indian sector during 2005/2006 SSW event, and their following studies showed that the obvious quasi-16-day periodic planetary wave in tropic stratosphere occurred about 60 days ahead of the 2005/2006 major SSW (Vineeth et al., 2010). In addition, the enhanced lunar tide during SSW should not be ruled out as the possible reason for the 14-day periodic variation in EEJ index and meridional movement of EIA crest shown in Figs. 2 and 3. Up to now, no explicit evidence and mechanism can clearly identify the origin of enhanced quasi-16day planetary wave in MLT region of low latitude during the SSW period. Nevertheless, the existence of the quasi-16-day periodic variation in MLT region in low latitude has been verified by direct observation in MLT or through the variations of EEJ. So it is reasonable to consider that the background atmospheric wind that interacts with different scale planetary waves and atmospheric tides plays an important role in the periodic variation of zonal electric field through electrodynamic process in ionospheric height, and it is finally manifested in the periodic variation of some ionospheric parameters in EIA region, such as EEJ, $h m \mathrm{~F} 2$, electron density and the location of EIA crest. According to Vineeth et al. (2007), Pedatella and Forbes (2009) and our study in this paper, it can be concluded that quasi-16-day periodic variation in the zonal equatorial electric field can be connected with the same periodic-scale planetary wave and/or modifications of the lunar tide. This periodic variation in the electric field changes electron density distribution in the low-latitude region via $\boldsymbol{E} \times \boldsymbol{B}$ drift and diffusion process along magnetic field lines, and finally leads to quasi-16-day periodic meridional movements of EIA crest.

Pedatella and Forbes (2009) found the quasi-16-day oscillation of electron content using in situ electron density at a near-constant height (about $345 \mathrm{~km}$ ) measured by CHAMP satellite and GPS TEC data in the geomagnetic latitude belt between $10^{\circ} \mathrm{N}$ and $20^{\circ} \mathrm{N}$ during the same time period. In our study, the quasi-16-day component of $f o \mathrm{~F} 2$ at Chongqing station is obvious, but Haikou ionosonde station does not show similar component. The reason may be that Chongqing station is always at the northern side of the EIA crest, so the variations of $f o \mathrm{~F} 2$ at this station have a good correlation with the movements of EIA crest. However, Haikou station is positioned near the average location of EIA crest as shown in Fig. 2, and the situation becomes more complicated. While the EIA crest moves periodically in the meridional direction, Haikou ionosonde station sometimes is located in the northern side of EIA crest and sometimes is located in the southern side of EIA crest. So besides the possible influence through photochemical process due to $h m \mathrm{~F} 2$ change (Pedatella and Forbes, 2009), the EIA crest movement might affect the variation of the peak critical frequency of F2 layer observed at Haikou station, which is near the average location of EIA crest. According to ionospheric continuity equation and equatorial plasma drift theory, the amount of the plasma transported from the lower ionosphere to the higher ionosphere is determined by the product of the vertical drift velocity and the equatorial plasma density in lower height of $\mathrm{F}$ region, so the variation of electron density in EIA region due to vertical drift process is determined both by the electron density and the electric field at lower ionospheric height. It is known that the electron density is mainly affected by the solar EUV irradiation flux that usually exhibits 27-day periodic variation, and the zonal electric field is more dependent on the atmospheric movements in the ionospheric dynamo region height that sometimes exhibit periodic variations in planetary wave scales (Oinates et al., 2008; Fejer, 1991; Forbes, 1996). Besides the large variation of the ionospheric electric field and electron density related to solar events and geomagnetic storms, the ionospheric zonal electric field and electron density sometimes exhibit some changes with different periodic scales and magnitudes during SSW period that make the electron density in ionospheric F2 peak height vary in a complicated manner. So to analyze the variation of the ionospheric electron density at a fixed position in lowlatitude regions, the possible influence of the periodic meridional movement of EIA crest should be considered.

The evolution of the polar stratospheric warming and its connection with the global enhancement of the quasi-16day periodic variation in the stratosphere and MLT region should have some similar features for different SSW events. Vineeth et al. (2010) have demonstrated similar patterns of the horizontal propagation of 16-day planetary wave in stratosphere from low to high latitude for different SSW events. Goncharenko et al. (2010b) studied the SSW impact on EIA for different SSW events and found the repeatable strong semidiurnal variation in vertical ion drift and largescale redistribution of electron density in the daytime. Here, it is only natural for us to identify the similar meridional movement from EIA crest data for other SSW years. Figure 8 gives the L-S periodogram of MLAT of EIA crest from GUAN GPS data and the EEJ in China low latitudes during 2002-2003 SSW (1 December 2002-31 March 2003). It can be seen that the similar quasi-16-day periodic component is revealed.

Although the quasi-16-day movement of EIA crest revealed in our study is based on GPS measurement only at China longitude, we can expect that this kind of meridional movement of EIA crest has a global scale, as similar periodic oscillation of global electron density is seen in CHAMP and TEC (Pedatella and Forbes, 2009). In order to verify this point, the $\mathrm{L}-\mathrm{S}$ periodogram of the location of EIA peak in 

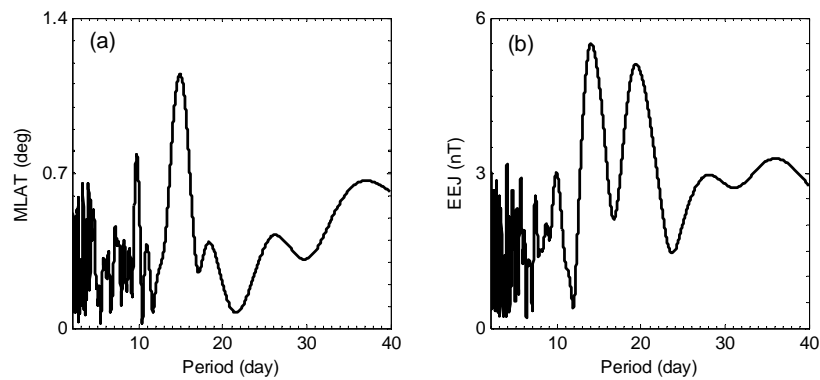

Fig. 8. Lomb-Scargle periodograms of the MLAT location of EIA crest above GUAN GPS stations (a) and EEJ (b) during 2002/2003 SSW.

East Asia and South American longitude during this SSW is given in Fig. 9. The locations of EIA used in this figure are derived from TEC map in two square regions (MLAT: $0-30^{\circ} \mathrm{N}$; Glong: $110-130^{\circ} \mathrm{E}$, and MLAT: $0-30^{\circ} \mathrm{S}$; Glong: $280-300^{\circ} \mathrm{E}$ ) that is obtained from daily MIT Automated Processing of GPS (MAPGPS) (Rideout and Coster, 2006) data with $1^{\circ} \times 1^{\circ}$ spatial resolution. It can be seen that the amplitude of the EIA movement in American longitude is much larger than that in East Asian region. This periodic meridional movement of EIA crest is global and will affect the ionospheric morphology over low- and middle-latitude region. There is no doubt that this finding is important for grasping the global ionospheric variation in low-latitude regions.

Besides the quasi-16-day periodic oscillation, upper atmosphere and ionosphere reveals other variations with periods ranging from 2 days to $2 \mathrm{yr}$. These different periodic variations may accompany the similar periodic movement of EIA crest. So further study of EIA movement to identify other periodicities and to reveal their connection to periodic variations in the atmosphere is helpful to understand the EIA morphology thoroughly. In the mean time, further case studies, and model and theoretical studies are necessary in order to understand the relationship between the quasi-16-day periodic movements of EIA crest and the variations of the other parameters in MLT and ionospheric region during SSW events and to identify its possible effect on the ionosphere in low-latitude regions.

\section{Summary}

Based on the MLAT location of the EIA crest derived from GPS data observed at China low-latitude region during the 2005/2006 SSW year, we report a quasi-16-day periodic meridional movement of EIA crest with the maximum amplitude of about $20 \%$ relative to the average location of EIA crest (equivalent to 2 degree in meridional direction in this longitudinal sector). In the same time period, this kind of quasi-16-day oscillation is also seen in EEJ and in $h m \mathrm{~F} 2$ parameters. However, Dst index and $f o \mathrm{~F} 2$ near average latitude

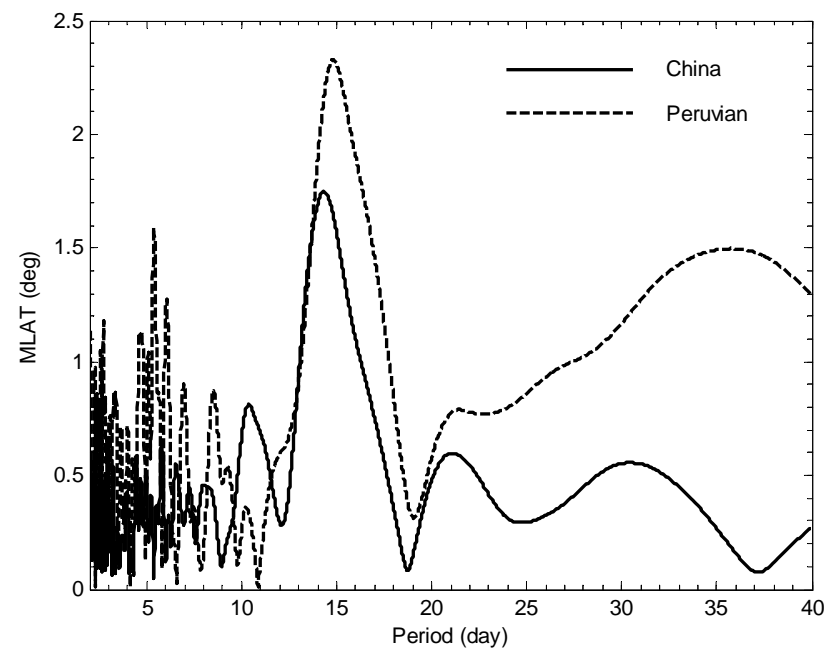

Fig. 9. L-S periodogram of the location of EIA peak in East Asia and South American longitude during this SSW.

of EIA crest exhibit a weak or unidentified quasi-16-day variation. The 16-day periodic component does not exist in F10.7 index. In addition, our study illustrates that this kind of 16day periodicity in EIA crest location was revealed during the periods of enhanced stratospheric planetary waves coupled with anomalous stratospheric zonal wind, and suggests that the temporal extent of the stratospheric wind anomaly might play an important role in the process. Such large-scale periodic meridional movement of EIA crest should be ascribed to the electro-dynamic process in the EIA region related to the enhanced quasi-16-day periodic atmospheric variation in ionospheric dynamo region. In addition, this large-scale periodic movement of EIA is global, and can affect the ionospheric morphology around the low-latitude belt near the EIA region during SSW periods.

Acknowledgements. The GPS data were from the Crustal Movement Observation Network of China. The geomagnetic data at BCL were from MAGDAS/CPMN and the geomagnetic data at YON were from China magnetometer network. The ionosonde data were from National Key Laboratory of Electromagnetic Environment. This research was jointly supported by the National Natural Science Foundation of China $(41174134,41274156)$ and National Important Basic Research Project of China (2011CB811405). L. Goncharenko has been supported through NSF grant AGS-1132267. X. H. Mo has been supported from Guangxi University for Nationalities (no. 2012QD016). We gratefully acknowledge National Center for Environmental Protection (NCEP) for providing public access to stratospheric data.

Topical Editor K. Hosokawa thanks P. R. Fagundes and D. Pancheva for their help in evaluating this paper. 


\section{References}

Abdu, M. A., Batista, P. P., Batista, I. S., Brum, C. G. M., Carrasco, A. J., and Reinisch, B. W.: Planetary wave oscillations in mesospheric winds, equatorial evening prereversal electric field and spread F, Geophys. Res. Lett., 33, L07107, doi:10.1029/2005GL024837, 2006.

Anderson, D., Anghel, A., Yumoto, K., Ishitsuka, M., and Kudeki, E.: Estimating daytime vertical $\boldsymbol{E} \times \boldsymbol{B}$ drift velocities in the equatorial F-region using ground-based magnetometer observations, Geophys. Res. Lett., 29, 1596, doi:10.1029/2001GL014562, 2002

Appleton, E. V.: Two anomalies in the ionosphere, Nature, 157, 691-693, 1946.

Bradley, P. A. and Dudeney, J. R.: A simple model of the vertical distribution of electron concentration in the ionosphere, J. Atmos, Terr. Phys., 35, 2131-2146, 1973.

Chau, J. L., Fejer, B. G., and Goncharenko, L. P.: Quiet variability of equatorial $\boldsymbol{E} \times \boldsymbol{B}$ drift during a sudden stratospheric warming event, Geophys. Res. Lett., 36, L05101, doi:10.1029/2008GL036785, 2009.

Chau, J. L., Aponte, N. A., Cabassa, E., Sulzer, M. P., Goncharenko, L. P., and Gonzalez, S. A.: Quiet time ionospheric variability over Arecibo during sudden stratospheric warming events, J. Geophys. Res., 115, A00G06, doi:10.1029/2010JA015378, 2010.

Eccles, V., Rice, D. D., Sojka, J. J., Valladares, C. E., Bullett, T., and Chau, J. L.: Lunar atmospheric tidal effects in the plasma drifts observed by the Low Latitude Ionospheric Sensor Network, J. Geophys. Res., 116, A07309, doi:10.1029/2010JA016282, 2011.

Fagundes, P. R., Pillat, V. G., Bolzan, M. J. A., Sahai, Y., BeckerGuedes, F., Abalde, J. R., and Aranha, S. L.: Observations of $\mathrm{F}$ layer electron density profiles modulated by planetary wave type oscillations in the equatorial ionospheric anomaly region, J. Geophys. Res., 110, A12302, doi:10.1029/2005JA011115, 2005.

Fejer, B. G.: Low latitude electrodynamic plasma drifts: A review, J. Atmos. Terr. Phys., 53, 677-693, 1991

Fejer, B. G.: Low latitude ionospheric electrodynamics, Space Sci. Rev., 158, 145-166, doi:10.1007/s11214-010-9690-7, 2011.

Fejer, B. G., Olson, M. E., Chau, J. L., Stolle, C., Lühr, H., Goncharenko, L. P., Yumoto, K., and Nagatsuma, T.: Lunar - equatorial ionospheric electrodynamic effects during sudden stratospheric warmings, J. Geophys. Res., 115, A00G03, doi:10.1029/2010JA015273, 2010.

Forbes, J. M.: Planetary waves in the thermosphere-ionosphere system, J. Geomag. Geoelectr., 48, 91-98, 1996.

Forbes, J. M. and Zhang, X.: Lunar tide amplification during the January 2009 stratosphere warming event: Observations and theory, J. Geophys. Res., 117, A12312, doi:10.1029/2012JA017963, 2012.

Goncharenko, L. P., Chau, J. L., Liu, H.-L., and Coster, A. J.: Unexpected connections between the stratosphere and ionosphere, Geophys. Res. Lett., 37, L10101, doi:10.1029/2010GL043125, 2010a.

Goncharenko, L. P., Coster, A. J., Chau, J. L., and Valladares, C. E.: Impact of sudden stratospheric warmings on equatorial ionization anomaly, J. Geophys. Res., 115, A00G07, doi:10.1029/2010JA015400, 2010b.

Hagan, M. E. and Forbes, J. M.: Migrating and nonmigrating diurnal tides in the middle and upper atmosphere excited by tropospheric latent heat release, J. Geophys. Res., 107, 4754, doi:10.1029/2001JD001236, 2002.

Immel, T. J., Sagawa, E., England, S. L., Henderson, S. B., Hagan, M. E., Mende, S. B., Fery, H. U., Swenson, C. M., and Paxton, L. J.: Control of equatorial ionospheric morphology by atmospheric tides, Geophys. Res. Lett., 33, L15108, doi:10.1029/2006GL026161, 2006.

Jin, H., Miyoshi, Y., Pancheva, D., Mukhtarov, P., Fujiwara, H., and Shinagawa, H.: Response of migrating tides to the stratospheric sudden warming in 2009 and their effects on the ionosphere studied by a whole atmosphere-ionosphere model GAIA with COSMIC and TIMED/SABER observations, J. Geophys. Res., 117, A10323, doi:10.1029/2012JA017650, 2012.

Lei, J., Thayer, J. P., Forbes, J. M., Wu, Q., She, C., Wan, W., and Wang, W.: Ionosphere response to solar wind high-speed streams, Geophys. Res. Lett., 35, L19105, doi:10.1029/2008GL035208, 2008

Limpasuvan, V., Thompson, D. W. J., and Hartmann, D. L.: The life cycle of the northern hemisphere sudden stratospheric warmings, J. Climate, 17, 2584-2596, doi:10.1175/15200442(2004)017<2584:TLCOTN>2.0.CO;2, 2004.

Lin, C. H., Liu, J. Y., Fang, T. W., Chang, P. Y., Tsai, H. F., Chen, C. H., and Hsiao, C. C.: Motions of the equatorial ionization anomaly crests imaged by FORMOSAT-3/COSMIC, Geophys. Res. Lett., 34, L19101, doi:10.1029/2007GL030741, 2007.

Liu, H., Yamamoto, M., Tulasi Ram, S., Tsugawa, T., Otsuka, Y., Stolle, C., Doornbos, E., Yumoto, K., and Nagatsuma, T.: Equatorial electrodynamics and neutral background in the Asian sector during the 2009 stratospheric sudden warming, J. Geophys. Res., 116, A08308, doi:10.1029/2011JA016607, 2011.

Lomb, N. R.: Least-squares frequency analysis of unequally spaced date, Astrophys. Space Sci., 39, 447-462, 1976.

Mannucci, A. J., Wilson, B. D., Yuan, D. N., Ho, C. M., Lindqwister, U. J., and Runge, T. F.: A global mapping technique for GPSderived ionspheric total electron content measursements, Radio Sci., 33, 565-582, doi:10.1029/97RS02707, 1998.

Mukhtarov, P., Andonov, B., Borries, C., Pancheva, D., and Jakowski, N.: Forcing of the ionosphere from above and below during the Arctic winter of 2005/2006, J. Atmos. Sol.-Terr. Phys., 72, 193-205, 2010.

Oinats, A. V., Ratovsky, K. G., and Kotovich, G. V.: Influence of the 27-day solar flux variations on the ionosphere parameters measured at Irkutsk in 2003-2005, Adv. Space. Res., 42, 639-644, doi:10.1016/j.asr.2008.02.009, 2008.

Pancheva, D. V. and Mitchell, N. J.: Planetary waves and variability of the semidiurnal tide in the mesosphere and lower thermosphere over Esrange $\left(68^{\circ} \mathrm{N}, 21^{\circ} \mathrm{E}\right)$ during winter, J. Geophys. Res., 109, A08307, doi:10.1029/2004JA010433, 2004.

Pancheva, D., Mitchell, N., Clark, R. R., Drobjeva, J., and Lastovicka, J.: Variability in the maximum height of the ionospheric F2-layer over Millstone Hill (September 1998-March 2000); influence from below and above, Ann. Geophys., 20, 1807-1819, doi:10.5194/angeo-20-1807-2002, 2002.

Parish, H. F., Forbes, J. M., and Kamalabadi, F.: Planetary wave and solar emission signatures in the equatorial electrojet, J. Geophys. Res., 99, 355-368, doi:10.1029/93JA02096, 1994.

Pedatella, N. M. and Forbes, J. M.: Modulation of the equatorial Fregion by the quasi-16-day planetary wave, Geophys. Res. Lett., 34, L09105, doi:10.1029/2009GL037809, 2009. 
Pedatella, N. M. and Forbes, J. M.: Global structure of the lunar tide in ionospheric total electron content, Geophys. Res. Lett., 37, L06103, doi:10.1029/2010GL042781, 2010.

Pedatella, N. M. and Liu, H.-L.: The influence of atmospheric tide and planetary wave variability during sudden stratosphere warmings on the low latitude ionosphere, J. Geophys. Res. Space Phys., 118, 5333-5347, doi:10.1002/jgra.50492, 2013.

Rastogi, R. G. and Klobuchar, J. A.: Ionospheric electron content within the equatorial F2 layer anomaly belt, J. Geophys. Res., 95, 19045-19052, 1990.

Rideout, W. and Coster, A.: Automated GPS processing for global total electron content data, GPS Solut., 10, 219-228, doi:10.1007/s10291-006-0029-5, 2006.

Sagawa, E., Immel, T. J., Frey, H. U., and Mende, S. B.: Longitudinal structure of the equatorial anomaly in the nighttime ionosphere observed by IMAGE/FUV, J. Geophys. Res., 110, A11302, doi:10.1029/2004JA010848, 2005.

Scargle, J. D.: Studies in astronomical time series analysis. II. Statistical aspects of spectral analysis of unevenly spaced data, Astrophys. J., 263, 835-853, 1982.

Sripathi, S. and Bhattacharyya, A.: Quiet time variability of the GPS TEC and EEJ strength over Indian region associated with major sudden stratospheric warming events during 2005/2006, J. Geophys. Res., 117, A05305, doi:10.1029/2011JA017103, 2012.
Vineeth, C., Pant, T. K., Devasia, C. V., and Sridharan, R.: Atmosphere-Ionosphere coupling observed over the dip equatorial MLTI region through the quasi 16-day wave, Geophys. Res. Lett., 34, L12102, doi:10.1029/2007GL030010, 2007.

Vineeth, C., Pant, T. K., Kumar, K. K., and Sumod, S. G.: Tropical connection to the polar stratospheric sudden warming through quasi 16-day planetary wave, Ann. Geophys., 28, 2007-2013, doi:10.5194/angeo-28-2007-2010, 2010.

Yamazaki, Y.: Large lunar tidal effects in the equatorial electrojet during northern winter and its relation to stratospheric sudden warming events, J. Geophys. Res. Space Phys., 118, 7268-7271, doi:10.1002/2013JA019215, 2013.

Yeh, K. C., Franke, S. J., Andreeva, E. S., and Kunitsyn, V. E.: An Investigation of Motions of the Equatorial Anomaly Crest, Geophys. Res. Lett., 28, 4517-4520, doi:10.1029/2001GL013897, 2001.

Zhang, D. H. and Xiao, Z.: Study of ionospheric response to the 4B flare on 28 October 2003 using International GPS Service network data, J. Geophys. Res., 110, A03307, doi:10.1029/2004JA010738, 2005.

Wan, W., Liu, L., Pi, X., Zhang, M.-L., Ning, B., Xiong, J., and Ding, F.: Wavenumber-4 patterns of the total electron content over the low latitude ionosphere, Geophys. Res. Lett., 35, L12104, doi:10.1029/2008GL033755, 2008. 